\title{
Lithuania's Security and Defence in 2017-2018: the International Context and New Research. Preface
}

The Research Centre of the General Jonas Žemaitis Military Academy of Lithuania, alongside its partners at Vilnius University and Vytautas Magnus University, present their readers with the sixteenth volume of the Lithuanian Annual Strategic Review, devoted to the security and defence topicalities of Lithuania and the Baltics in 2017-2018.

As is typical each year, the period from fall 2017 to the end of summer 2018 was rich in developments important for the security and defence of Lithuania. The probability of changes at the level of the international system was primarily associated with the change in the USA administration and Donald Trump's term in office. During the electoral campaign, the future president, contrary to his predecessors, assessed the North Atlantic Treaty Organization rather critically and claimed that the contribution of European allies to the enhancement of the defensive capabilities of the Alliance are too small.

Trump's position had a dual impact on the development of the European security. On one hand, it encouraged Europeans, among them Lithuania, to start increasing defence financing. On the other hand, it served as an additional impulse to make further steps to the European integration in the area of defence. At the end of 2017, the European Union began to implement the provisions of the Lisbon Treaty on Permanent Structured Cooperation. Certainly, it is a small, but nevertheless important, step towards closer European cooperation. This is particularly significant keeping in mind the on-going separation of the United Kingdom from the European Union (Brexit) and the unclear perspective of this important country. This time, Lithuania, without nagging doubts, also confirmed its intention to participate in the cooperation, and even undertook the initiative, to establish rapid reaction teams for responding to cyberattacks.

Meanwhile, during the discussed period, at the level of the international system and within the European security space, dynamic processes were taking place. In the eastern neighbourhoods of Lithuania one could observe the opposite picture, i.e. paraphrasing Erich Maria Remarque "Im Osten Nichts Neues". The political and military tension between Russia and the Western world was still lingering or, for all we know, Russia’s "hybrid warfare" against 
almost the whole world, the warfare that no one exactly knows either when it began or what its objectives are, kept going on. The still smouldering conflict with Ukraine, the tireless propaganda campaign against the Baltic states, the financial support of the populist parties in Western Europe, encroachments employing chemical weapons or attempts, via the means of communication, to manipulate the electoral campaigns even in the United States testified to that. In March 2018, although presidential elections were held in Russia, as it was expected they did not bring any surprises or, the more so, changes.

While we had the possibility to observe rather dynamic processes in the West and a certain stagnation in the East, it was possible to register at the national and neighbourly cooperation level a distinct consistency and systemic development of the implementation of set security and defence plans and guidelines. In 2017, the Baltic states and Poland hosted combat groups of NATO forward presence battalions, Lithuania kept consistently increasing the financing of the national defence in 2017-2018, signed the agreement on the procurement of a medium-range air defence system, and conducted call-ups to the regular, mandatory basic military service according to the plan. In June 2018, the largest ever international exercise, "Saber Strike", where about 18,000 military personnel from 19 NATO countries participated, was conducted simultaneously in all three Baltic states and Poland.

All these developments and processes no doubt will attract the attention of the researchers of the Research Centre at the Military Academy of Lithuania and are, to a certain extent, analysed from various aspects already in this collection of research papers. It is worth mentioning that an unusually large number (as many as fourteen!) of papers are published in this edition. Continuing the established tradition, we have categorized them into four groups.

The first group, "The Global International System and Lithuania", is comprised of four studies that, in one way or another, place Lithuania and its security and defence dilemmas into a broader international systemic context. Egidijus Vareikis, for the celebration of the Centennial of the Restored Lithuania, prepared a review where he discusses the geopolitical prognoses of the development of Lithuania and the entire North Eastern European region for the coming hundred years. According to the author, in the geopolitical visions of the $21^{\text {st }}$ century, the Baltic states are seen as a part of the integrated Euro-Atlantic space enjoying a good possibility to become members of the new power centre forming in Central Europe or a strong periphery of North Western Europe. Egle Murauskaitè, in her study "Nuclear Matters: Lithuanian Security Culture in the Context of NATO Trends", traces and contrasts two 
parallel processes: the development of Lithuanian security culture, and the evolution of NATO's relation to nuclear weapons. The researcher registers "the subtle rhetorical dissonance", because, as she puts it, the nuclear nature of NATO's deterrent has largely escaped the Lithuanian public discourse. Gintas Gumbrys prepared a study providing comprehensive information on Lithuania's military contribution to the assurance of international security and stability - the participation of Lithuanian military personnel in international operations and European Union training missions from 2004-2017. From this historical perspective, the author attempts to find the connection between the accumulated participation experience and potential military contributions of Lithuania to international operations in the future. In her article, Agniete Žotkevičiūté-Banevičiene explored the problems of the cultural awareness of military personnel participating in international operations and compared its manifestation in military doctrines and other documents regulating the activity of the armed forces and the military service in major NATO states and Lithuania. On the grounds of the conducted research, the author formulates recommendations on how Lithuania can and must align with major NATO states shaping cultural awareness guidelines in strategic documents and development programs.

The second part of the Lithuanian Annual Strategic Review - "The Changing European Security Environment” - consists of three studies. Eitvydas Bajarūnas and Vytautas Keršanskas explore particularly relevant topic after Russia's war in Ukraine and about the threats of hybrid warfare and potential responses to them. The study surveys both the theoretical considerations of the definition of hybrid warfare and threat concepts and the practical aspects of the problem including the means of hybrid impact employed by Russia as well as Lithuania's, the European Union's, and NATO's measures and actions of fighting them. Viljar Veebel and Illimar Ploom assess the credibility of the deterrence posture provided by NATO in avoiding Russia's potential aggression against the Baltic states. The focus of the analysis covers both the physical capabilities of potential parties to the conflict and behavioural-ethical aspects related to the current security environment. The article demonstrates the challenges for the Alliance's deterrence strategy and makes several suggestions of how to increase the credibility of NATO's deterrence strategy to avoid Russia's potential aggression.

Klaidas Kuchalskis, in his article "Organised Crime: New Challenges and Response Addressing Them", searches for the answer of how and why this danger is relevant to national security. The author analyses this phenomenon 
from the perspective of Lithuania and from that of the European Union and comes to the unambiguous conclusion - taking into consideration the ever growing hybrid threats, it becomes obvious that organized crime poses a great and ever increasing threat to Lithuanian national security and to that of the whole of Europe.

The third, traditional part of the journal, "Lithuania's Eastern Neighbourhood", again focuses on Russia, the greatest neighbour to the East. This time, Russia's policy and warfare has attracted the attention of three researchers. Daivis Petraitis explores the military exercise Zapad 2017, conducted a year ago by Russia and which attracted the attention of many observers. According to the author, who carried out the research and accumulated the available information, it may be stated that during the exercises it was demonstrated that the concept and plan of a potential war against a strong adversary in the West was tested. The essence of the latter is detailed, planned, and carefully coordinated in the time and space actions of the military forces. The researcher draws the conclusion that the current political and military command of Russia remain faithful to the traditions and philosophy of Prussia's General Staff while seeking to employ modern technological progress for still greater effectiveness. Algirdas Revaitis, in his study devoted to the modern military discourse in Russia's military thought, focused on publicly accessible texts and speeches prepared by Russian officers, warfare experts, and analysts. The author stated that Russia's military practices in Eastern Ukraine influenced its attitude to modern warfare, in particular which new warfare types (terminology) surfaced in the Russian military glossary. Having completed the analysis, the researcher came to an intriguing conclusion that the developers of Russian military thought are rather inclined to imitate the military experiences of Western states, particularly those of the USA, yet evade the conceptualization of their latest military practices as visions of future warfare. Raimundas Lopata prepared a study devoted to the geopolitical status transformation of Russia's Kaliningrad Oblast (region) after the annexation of Crimea and aggression against Ukraine. The research reveals that Moscow consistently renounces the idea to eventually turn Kaliningrad into a geopolitical connection linking Russia with the West. Russia is unambiguously transforming the region into a military outpost, at the same time applying a more severe control in the areas of social, economic, and political processes and sparing no effort to maintain the energetic life of the region under the conditions of isolation (or cutoff) and transit restrictions. 
The fourth part of the Lithuanian Annual Strategic Review traditionally analyses urgent aspects, problems, and cases of Lithuanian national security. This time, readers have the opportunity to get acquainted with four studies. Vytautas Jokubauskas, in his study "Territorial Defence and Partisan Resistance (Lithuania's Experience)" gets deep into the historical experience of the Lithuanian territorial defence and partisan operation. In the author's opinion, this can have a tangible, applicable importance because, on one hand, in the first part of the $20^{\text {th }}$ century, Lithuania not only considered and planned these concepts, but more than once applied them in practice. On the other hand, the geographical localization of the country, as well as the distribution of eventual conflict sources, in comparison with the inter-war period did not essentially change. Aušra Pociene researched the possibilities to attract young people to the regular mandatory basic military service and, on the grounds of abundant quantitative research, drew the conclusion in her article that the wish to learn to defend one's own family and the Motherland, as well as the post-modern motive to experience adventure and trials, were the main reasons of the first volunteer conscripts. Still, in the author's opinion, it should be admitted that young men are attracted to the regular mandatory basic military service not only by patriotic idealistic arguments but also by rational calculations. The desire to perform mandatory military service now so as not to do it later was also a significant reason for volunteering during the first round of the call-up. Audronè Petrauskaite and Laurynas Šaltenis, in the article "Impact of Ethical Problems of the Intelligence Activity for National Security", engaged in the examination of an interesting theoretical problem that has significant practical implications as well. The article systematizes insights on the grounds of scientific literature where the individual and organization-level context and moral reasoning assumptions influencing the chosen behavioural strategies and their consequences at the level of the individual, group, organization and state are analysed. On the grounds of the presented theoretical analysis, the authors constructed the Initial Behavioural Model of the Integral Intelligence Official that could serve as the reference point for further structured discussion. Gintaras Šumskas and Irmina Matonyte, in their study "Impact of the News Media Use for the Assessment of Military Threats" analysed concepts and assessments of military threats on the grounds of the news media theories and data from representative Lithuanian public opinion polls. According to the authors, the research showed that the impact of the news media usage is enhanced by certain qualities of the individual political competence and that gutter press and 
Russian TV, as well as qualitative press, affect concepts of military threats, in which sets of factors forming concepts of military threats are different. The authors emphasize that the extent of the news media impact is mostly exerted by the national belonging of the individual, education, income, participation in elections, political awareness, and interpersonal communication on political topics, as well as leftist-rightist self-identification.

Vilnius, August 2018

Gediminas Vitkus

Editor-in-Chief

Military Academy of Lithuania 


\section{Content}

Lithuania's Security and Defence in 2017-2018:

the International Context and New Research. Preface

Gediminas Vitkus

The Global International System and Lithuania

On the Road to the Second Century: the Geopolitical Future

of the Baltic States in the Visions of Politicians and Political Scientists.

Egidijus Vareikis

Nuclear Matters: Lithuanian Security Culture in the Context

of NATO Trends.

Egle Murauskaité

Lithuania's Contribution to International Operations:

the Current Situation and Potential Scenarios.

Gintautas Gumbrys

Modern Practice of Military Cultural Awareness:

Lithuania among the Great Powers

Agnietè Žotkevičiūtè - Banevičiené

The Changing European Security Environment

Hybrid Threats: Analysis of Content, Challenges Posed and Measures to Overcome

Eitvydas Bajarūnas, Vytautas Keršanskas

The Deterrence Credibility of NATO and the Readiness of the Baltic States

to Employ the Deterrence Instruments

Viljar Veebel, Illimar Ploom

Organised Crime: New Challenges and Response Addressing Them. Klaidas Kuchalskis

Lithuania's Eastern Neighbourhood.

The Anatomy of Zapad-2017: Certain Features of Russian

Military Planning

Daivis Petraitis

Contemporary Warfare Discourse in Russia's Military Thought Algirdas Revaitis

Kaliningrad in the European Security Architecture after the Annexation of Crimea

Raimundas Lopata

National Security and Defence Issues

Territorial Defence and Partisan Resistance (Lithuania's Experience)

Vytautas Jokubauskas

Possibilities to Attract Lithuanian Young People to Permanent

Compulsory Primary Military Service Aušra Pociené

The Interaction between Intelligence Operations and Ethics in the Context

of National Security: a Theoretical Review of the Problem

Audronè Petrauskaiteè, Laurynas Šaltenis

Impact of the Mass-Media on the Assessment of Military Threats

Gintaras Šumskas, Irmina Matonytė 